BULLETIN Bulletin hispanique

HISPANIQUE Université Michel de Montaigne Bordeaux

119-1 | 2017

Autorité et pouvoir dans le théâtre du Siècle d'Or

\title{
Autoridad y poder en el teatro del Siglo de Oro
}

Géneros y casos

Ignacio Arellano

\section{(2) OpenEdition}

Journals

Edición electrónica

URL: http://journals.openedition.org/bulletinhispanique/4739

DOI: 10.4000/bulletinhispanique.4739

ISBN: 979-10-300-0142-6

ISSN: 1775-3821

Editor

Presses universitaires de Bordeaux

Edición impresa

Fecha de publicación: 15 junio 2017

Paginación: 29-44

ISBN: 979-10-300-0141-9

ISSN: 0007-4640

Referencia electrónica

Ignacio Arellano, «Autoridad y poder en el teatro del Siglo de Oro », Bulletin hispanique [En línea],

119-1 | 2017, Publicado el 15 junio 2020, consultado el 10 septiembre 2020. URL : http://

journals.openedition.org/bulletinhispanique/4739; DOI : https://doi.org/10.4000/bulletinhispanique. 4739

Tous droits réservés 


\title{
Autoridad y poder en el teatro del Siglo de Oro. Géneros y casos
}

\author{
Ignacio Arellano \\ GRISO-Universidad de Navarra
}

Larticle examine divers aspects de l'autorité et du pouvoir dans le théâtre du Siècle d'Or en fonction des conventions et de la structure des différents genres dramatiques : autos religieux, pièces comiques, tragédies, comédies burlesques, etc. Il montre que la représentation du thème obéit non seulement à des impératifs éthiques mais aussi aux impératifs esthétiques liés à chaque genre theâtral.

Mots-clés: autorité, pouvoir, genre dramatique, thêâtre du Siècle d'Or.

El artículo examina diversos aspectos de la autoridad y el poder en el teatro del Siglo de Oro en relación con las convenciones y estructuras de los distintos géneros dramáticos: autos sacramentales, comedias cómicas, tragedias, comedias burlescas, etc. mostrando cómo el tratamiento del tema obedece no solo a imperativos éticos sino también a los de estética teatral pertinente.

Palabras clave: autoridad, poder, géneros, teatro del Siglo de Oro.

This article examines diverse aspects of authority and power in the theatre of the Golden Age in relation to conventions and structures of various dramatic genres: allegorical plays, comedies, tragedies, burlesque comedies, etc.. It aims at showing how the treatment of the subject obeys not only ethical but also æsthetic imperatives linked with every the theatrical genre.

Keywords: authority, power, dramatic genres, Golden Age theater. 
G 1 campo de la autoridad y el poder en el teatro del Siglo de Oro es de una C vastedad interminable, como por otra parte se advierte en otras muchas áreas literarias. La línea de investigación que desde hace algunos años venimos desarrollando cuatro equipos de París, Munster, Oxford y Pamplona ${ }^{1}$, junto con otros colaboradores, va poniendo de manifiesto numerosas dimensiones de este gran tema que cruza todos los géneros o especies dramáticas.

En esta oportunidad me interesa precisamente plantear una reflexión de conjunto, desde la perspectiva de los géneros, que pudiera servir para establecer algunas orientaciones básicas sobre los enfoques probables en la escena barroca, proponiendo algunos pocos ejemplos de los infinitos posibles, sin entrar en análisis pormenorizados de las áreas del teatro áureo en relación con el poder y sus formas.

Es conocida la postura de Maravall ${ }^{2}$, que interpreta todo el teatro barroco como una máquina de propaganda monárquico nobiliaria al servicio del poder político e ideológico dominante, visión que no tiene en cuenta la variedad de posturas de los autores ni, sobre todo, la variedad de perspectivas genéricas.

\section{Perspectiva Panegírica Del poder}

Sin duda hay muchas comedias que pertenecen a la orientación señalada por Maravall: todas las piezas panegíricas, las comedias genealógicas en exaltación de una familia noble, las loas cortesanas y fiestas mitológicas de gran espectáculo palaciego...

La relación de ingenios auriseculares que ejercieron de secretarios de nobles, por ejemplo, sería larga. Vélez de Guevara mantiene una constante vinculación a la nobleza que se manifiesta en el tratamiento y selección de asuntos de sus comedias, igualmente vinculados a esa aristocracia a la que sirve. Una buena parte de las comedias de Lope entran en el denominado género genealógico. Bances Candamo es poeta eminentemente áulico...

Tomemos el ejemplo de la única comedia conocida de Quevedo, Cómo ha de ser el privado, pieza en elogio de Olivares y del rey ${ }^{3}$.

1. Ver para esta línea y algunos de sus desarrollos y actividades la página http://www.unav. edu/evento/autoridad-poder/. Este artículo se inserta en el marco concreto del proyecto de investigación FFI2014-52007-P, «Autoridad y poder en el teatro del Siglo de Oro. Estrategias, géneros, imágenes en la primera globalización", -financiado por el Ministerio de Economía y Competitividad-y del Programa Consolider-Ingenio 2010, CSD2009-00033, del Plan Nacional de Investigación Científica, Desarrollo e Innovación Tecnológica del Gobierno de España.

2. José Antonio Maravall, La cultura del Barroco, Barcelona, Ariel, 1980, passim: «la monarquía culmina un complejo de intereses señoriales restaurados» (p. 71); «una vuelta a la autoridad, a la estructura aristocrática de los vínculos de dependencia y al régimen de poderes privilegiados» (p. 73); «el Barroco español, bajo el vértice insuperable de la monarquía, está regido por la inadaptada clase de la nobleza tradicional» (p. 80); caracteriza al Barroco el «fortalecimiento de los intereses y poderes señoriales, como plataforma sobre la que se arma la monarquía absoluta» (p. 89); etc.

3. Ver nuestro estudio preliminar, con repaso del estado de la cuestión en Quevedo, Teatro 
La mayor parte de la obra se dedica al retrato del marqués de Valisero -anagrama de Olivares-, valido ideal caracterizado por su invariable lealtad, espíritu de sacrificio, capacidad de trabajo, servicio al rey y estoicismo personal.

Se trata, en suma, de una pieza de propaganda política, que tiene por objeto la exaltación del valido perfecto encarnado por Olivares. Esta característica ha influido decisivamente -para provocar casi siempre juicios negativos- en la valoración que la crítica ha hecho de la comedia. Gregorio Marañón sintetizaba esta actitud al afirmar que Cómo ha de ser el privado «es una defensa tan cínica de Olivares que produce una reacción de antipatía en el lector» ${ }^{4}$. Más severo todavía es Raimundo Lida:

Las continuas alabanzas de Olivares estorban el movimiento dramático y lo llevan al borde de la parálisis. Esa monótona adulación ya sería bastante para minar por dentro la vida de la obra, pero aun la adulación misma se dispersa. Sentimos una y otra vez que si el drama no marcha es porque el autor se empeña en adular en todas direcciones: al valido, al rey, a la infanta 5 .

En reacción contra esta lectura bastante obvia surgen modernamente interpretaciones opuestas, que perciben un ataque más o menos agudo a Olivares y al mismo rey. Frederick de Armas, por ejemplo, sugiere toda una serie de críticas contra el nuevo monarca:

una lectura detenida muestra cuatro áreas problemáticas en la presentación de Fernando/Felipe IV: su crueldad, su afeminamiento, su homoerotismo y su donjuanismo ${ }^{6}$.

Hay que decir que ninguna de esas áreas puede demostrarse con el texto de Quevedo7, como tampoco son aceptables las afirmaciones de Iglesias de que «esta comedia en concreto muestra muchas más críticas sobre Olivares y Felipe IV que buena parte de las obras del periodo entre principios de 1621 y $1629 \prime^{8}$. Por el contrario, parece poco discutible que se trata de una pieza laudatoria en favor de Olivares, como muchas otras producciones del Siglo de Oro, relacionadas con el mecenazgo y y la propaganda ideológica y política.

La búsqueda de críticas en piezas de panegírico cortesano es anacrónica y poco verosímil. Resulta poco admisible pensar que lo que un crítico del siglo

completo, ed. Arellano y García Valdés, Madrid, Cátedra, 2011.

4. Ver Gregorio Marañón, El conde duque de Olivares, Madrid, Espasa Calpe, 1972, pp. 126 yss.

5. Raimundo Lida, Prosas de Quevedo, Barcelona, Crítica, 1981, p. 162.

6. Frederick de Armas, «En dos pechos repartidos»: Felipe IV y su valido en Cómo ha de ser el privado", Hispanófila, 2004, 140, pp. 10-11.

7. Ver la discusión al respecto, con argumentos más extensos en el prólogo a la edición citada en Teatro completo.

8. Rafael Iglesias, «El imposible equilibrio entre el encomio cortesano y la reprimenda política: hacia una nueva interpretación de Cómo ha de ser el privado de Quevedo", La Perinola, 2005, 9, pp. 289, 295.

9. Ver sobre el papel de mecenas del rey y de Olivares las observaciones de John C. Elliot, El Conde-Duque de Olivares, Barcelona, Crítica, 1990, pp. 187 y ss. 
XXI percibe, habiendo perdido muchas claves de los textos, no lo percibirían las supuestas víctimas de los ataques (Olivares o el rey) y que permitirían representar en los escenarios cortesanos piezas contra su autoridad.

Caso ejemplar es el que afecta a las comedias de fábrica y fábulas de espectáculo de Bances Candamo ${ }^{10}$, dramaturgo oficial de Carlos II.

La imagen del poder que Bances proyecta a través de su obra se manifiesta ya en la exaltación de los monarcas de la casa de Austria, especialmente en la del monarca a quien sirve Bances, es decir, Carlos II. Esta imagen directa del rey coetáneo se halla ya en las loas que abren las representaciones y que recogen las circunstancias concretas de la fiesta, como las loas de los autos El primer duelo del Mundo y El gran químico del Mundo, o de las comedias La restauración de Buda, o Duelos de Ingenio y Fortuna: antes de que se inicie la representación de esta última, los espectadores pueden ver la pintura del telón, que representa a los Héroes de la Fama en torno a Carlos II:

En medio de ellos se elevaba un pedestal, a quien coronaba con su huella una estatua de oro del rey nuestro, señor armado, cuya diestra mano blandía el real cetro, fatigándole la siniestra dos orbes, sujetos a la circulada coyunda de una corona y la Fama estaba en acción reverente ${ }^{11}$.

Parte de la crítica que ha estudiado a Bances no concibe cómo pueda conciliarse esta exaltación «desmedida» con la realidad histórica concreta de un Carlos II enfermizo, impotente y malformado. García Castañón ${ }^{12}$ llega a suponer que este tipo de elogios son irónicos, pero conviene recordar lo que señala Julián Gállego a propósito de los retratos de los reyes:

esos rostros largos, esas narices caídas, esas mandíbulas prognatas, esos belfos, ese tipo de fisonomía que hay quienes ven en nuestro tiempo como denuncia de la decadencia de una dinastía y de una familia determinada, la de los Habsburgos, fueron en el seiscientos la encarnación de la idea de la majestad en una cara humana ${ }^{13}$.

No faltan -como se verá- en el Siglo de Oro las visiones negativas y aún descarnadas del poder y los malos monarcas, ni ataques a veces feroces contra los validos, si no directamente contra los reyes. Pero es difícil encontrarlas en un dramaturgo oficial, salvo en casos tan complejos como el de Calderón (que no es comparable a Bances) pero sobre todo es difícil encontrarlas en las

10. Ver Ignacio Arellano «La imagen del poder en el teatro de Bances Candamo, poeta áulico de Carlos II», RILCE. Revista de filología hispánica, 2010, 26.1, pp.23-36. http://dadun.unav. edu/handle/10171/20716.

11. Francisco Antonio Bances Candamo, Poesías Cómicas. Obras póstumas de D. Francisco Bances Candamo, impresas en dos tomos en Madrid por Blas de Villanueva, en 1722, a costa de Joseph Antonio Pimentel, mercader de libros en la Puerta del Sol. I, pp. 224-225.

12. Santiago García Castañón, "La autoridad real en el teatro de Bances Candamo», en Looking at the "Comedia" in the Year of the Quincentennial (Symposium on Golden Age Drama), ed. B. Mujica, S. D. Voros y M. D. Stroud, Lanham, MD, University Press of America, 1993, p. 232.

13. Julián Gállego, Visión y simbolos en la pintura española del Siglo de Oro, Madrid, Cátedra, 1991, p. 231. 
circunstancias de emisión y recepción en las que se sitúan las comedias áulicas de Bances. Se desprende de estas obras la imagen del rey como un ser superior, de tal excelencia que la poseen incluso los monarcas infieles o bárbaros.

El poder de los reyes es absoluto. No se admiten las rebeliones populares (ver La restauración de Buda, Poesías cómicas, I, p. 147) ni se plantea nunca el tiranicidio, poco pertinente por lo demás a propósito de los ejemplares de rey que saca Bances a escena, raras veces negativos y nunca extremados en maldad o corrupción.

Pero, como corresponde a la doctrina política de la época, el absolutismo del poder tiene límites: no es arbitrario, sino sometido a la justicia.

Las pocas orientaciones que pueden darse al rey hay que proponerlas con mucho tacto y guardando el debido respeto: de ahí que no se le dirijan advertencias directas, sino por medio de obras de teatro que mantengan el decoro. El pasaje del Teatro de los teatros en el que acuña su fórmula del «decir sin decir» ha dado base para interpretaciones de su obra en clave de crítica política, astuta y denunciadora, en la línea de Duncan Moir, editor de su tratado teórico, donde escribe Bances:

son las comedias de los reyes unas historias vivas que sin hablar con ellos les han de instruir con tal respecto que sea su misma razón quien de lo que ve tome las advertencias, y no el ingenio quien se las diga. Para este decir sin decir ¿quién dudará que sea menester gran arte? ${ }^{14}$

Según Moir, que interpreta mal la fuente de una anécdota sobre Alejandro Magno y el sentido de la misma ${ }^{15}$ que aplica al disimulo político: «este trozo es la clave esencial de todo arte dramático de Bances -es un decir sin decir político-», visión que con matices diversos comparten otros estudiosos ${ }^{16} \mathrm{y}$ que he discutido en varios trabajos que no repetiré aquí. Para Bances se trata en realidad de una restricción de la crudeza con que el dramaturgo podría presentar sus lecciones. Muestra todo lo contrario de una actitud de denuncia más o menos subversiva o escandalosa. No es original de Bances, sino doctrina estética y política común.

14. Francisco Antonio Bances Candamo, Teatro de los teatros de los pasados y presentes siglos, ed. Duncan Moir, London, Tamesis Books, 1970, p. 57.

15. Ibid., p. 72, nota 37 y pp. XCV-XCVI. Ver para la discusión del sentido de la frase y de la anécdota aducida de Alejandro con los tres pintores Ignacio Arellano, "Bances Candamo, poeta áulico. Teoría y práctica en el teatro cortesano del postrer Siglo de Oro», Tübingen, Iberoromania, 1988, 27-28, pp. 42-60.

16. Ver Carmen Díaz Castañón, «Bances Candamo y su teatro político», Cuadernos del Norte, 1980, 6, pp. 74-82, y «El esclavo en grillos de oro. Acercamiento al teatro político de Bances Candamo", en Actas del Coloquio Teoría y realidad del teatro español del siglo XVII. La influencia italiana (Roma, 16-19 de noviembre de 1978), Roma, Instituto Espańol de Cultura y de Literatura de Roma, 1981, pp. 387-418. También su prólogo a El esclavo en grillos de oro en Francisco Antonio Bances Candamo, El esclavo en grillos de oro. La piedra filosofal, ed. Carmen Díaz Castańón, Oviedo, Caja de Ahorros de Asturias, 1983; Ver María Cristina Quintero, «Political Intentionality and Dramatic Convention in the Teatro palaciego of Francisco Bances Candamo", Revista de Estudios Hispánicos, 1986, 20, pp. 37-53. 
Esta exaltación dramática de la monarquía se percibe intensamente en las loas y autos sacramentales de Calderón.

Muy principalmente se acusa una clara y progresiva intencionalidad de mitificación política de la casa de Austria, que aparece con mucha evidencia especialmente en el corpus calderoniano. Enrique Rull ${ }^{17}$ ha dedicado algunos trabajos a esta dimensión construyendo una teoría sobre la función teológico política de la loa y auto sacramentales.

El uso de loas y autos sacramentales para fines que podemos llamar políticos tampoco parece raro en una época y en un país donde Iglesia y Estado guardan relaciones tan estrechas, y donde existe una corriente panegírica divinizadora de la monarquía. Calderón es el maestro de este tipo de auto de circunstancias: El nuevo palacio del Retiro, El valle de la zarzuela, La segunda esposa, Triunfar muriendo, El lirio y el azucena, El segundo blasón del Austria... Se funden las alusiones a la vida de Cristo y la Casa Real, se mixtura la historia sagrada y la profana... Lo que hace Calderón en algunos de los autos principales de esta categoría es aliar su visión de un universo ordenado regido por los designios de Dios, a la función rectora de la dinastía austriaca, a la que se considera vicaria de Dios en la Tierra, encargada de llevar a este mundo el orden ideal que responde a los planes de Dios.

Aunque en este género sea rara no falta alguna postura crítica precisamente provocada por circunstancias de la realidad histórica que constituye la materia argumental de un determinado auto, lo que se percibe con claridad en una pieza como El nuevo palacio del Retiro, cuyas dimensiones políticas han sido espléndidamente estudiadas por Paterson en el prólogo de su edición crítica, y en otros trabajos, donde pone de relieve que este auto «lejos de crear un mundo exclusivamente supraterrestre prepolítico, ideal, está al contrario transido de las tensiones y divisiones que figuraban la escena política en aquel entonces» ${ }^{18}$.

En el diseño de la alegoría Felipe IV representa a Cristo, la reina Isabel a la Iglesia y el valido, Olivares, al Hombre, nombrado alcaide del nuevo palacio del Retiro, imagen de la Jerusalén celestial. En la parte historial de El nuevo palacio del Retiro se pueden distinguir los intensos conflictos de poder que en esos momentos se desarrollan en el ámbito de la corte.

Uno de ellos se refiere a las facciones de secuaces y opositores a Olivares, y se trasluce en la evocación de una de las actividades festivas de la inauguración

17. Enrique Rull, «Hacia la delimitación de una teoría político-teológica en el teatro de Calderón", Calderón, Actas del Congreso Internacional sobre Calderón y el teatro español del Siglo de Oro, Madrid, CSIC, 1983, vol. II, pp. 759-767, y «Función teológico política de la loa», Notas y estudios filológicos, (Pamplona, UNED), 1985, 2, pp. 33-46, y en Apuntes sobre la loa sacramental y cortesana. Loas completas de Bances Candamo, (ed. de Ignacio Arellano, Kurt Spang y María Carmen Pinillos), Kassel, Reichenberger, 1994, pp. 25-35. También Ignacio Arellano, «Texto y contexto de El segundo blasón de Austria, auto sacramental de Calderón», en Homenaje al profesor Alberto Navarro, ed. María Luisa Lobato, Kassel, Reichenberger, 1990, pp. 17-39.

18. Alan G. K. Paterson, Introducción a Pedro Calderón de la Barca, El nuevo palacio del Retiro, Pamplona / Kassel, Universidad de Navarra / Reichenberger, 1998. p. 322. Uso en las líneas que siguen algunas observaciones de Ignacio Arellano, "Conflictos de poder en los autos sacramentales de Calderón», Studi Ispanici, 2011b, 36, pp. 67-85. 
del palacio, el juego de la sortija (vv. 1231-1258), que Paterson ha calificado de "palimpsesto político». Intervienen en este juego a lo divino dos cuadrillas de nobles, una de ellas capitaneadas por «un condestable», mientras el «otro condestable» no ha competido:

Y si quieres ver en cuanto
hay alegoría, hay misterio,
un Condestable ha corrido
y otro no, que fuera exceso
que viéramos dos estables,
adonde un Rey solo vemos,
que siendo el estable él solo,
de justicia y de derecho,
por no oponérsele dos,
enfermó uno de respeto. ${ }^{19}$

Para participar en el juego histórico ${ }^{20}$ estaban preparados el Condestable de Castilla (don Bernardino Fernández de Velasco) y el de Navarra (don Fernando Álvarez de Toledo). El de Castilla era cercano colaborador del Conde-Duque y el de Navarra enemigo abierto de Olivares, y acompañó a su padre, el sexto Duque de Alba, en el destierro a fines de 1634, después de una larga historia de hostilidad entre el valido y los de la casa de Toledo ${ }^{21}$. Los grandes de la corte forman las cuadrillas de justadores. Como señala Paterson,

Si leemos el texto como un palimpsesto político, llama la atención el perfecto equilibrio entre la "parentela» de Olivares y los enemigos políticos más temibles del Conde Duque. [...] El balance entre las facciones contemporáneas es tan exacto que desafía la mera coincidencia. Puede ser que Calderón, mediante el equilibrio que logra entre los bandos opuestos, intente disipar la confrontación seglar en el mundo idealizado del auto. [...] Pero tal lectura ideal requiere como premisa la realidad terrestre, y tanto aquí como en la cuestión judía, es impensable que un público contemporáneo (entre ellos los Consejos de Estado) dejara de intuir la confrontación política que subyace en la parada de los magnates celestiales. ${ }^{22}$

Un segundo componente conflictivo lo constituye el tema del sistema sinodal de los Consejos frente a la inclinación de Olivares a las Juntas especiales. En un largo pasaje (vv. 1131 y ss.) se describe el sistema de los consejos de gobierno, exaltando a los Consejos de Castilla, Indias, Órdenes, de Guerra, de la Inquisición, etc.), presididos en la alegoría por los Apóstoles. Olivares había desplazado a menudo los Consejos en favor de las Juntas especiales ${ }^{23}$; en 1634, fecha del auto, se crearon por lo menos catorce juntas, de manera que El nuevo palacio podría leerse en este punto como texto de oposición.

19. Pedro Calderón de la Barca, El nuevo palacio del Retiro, ed. Alan G. K. Paterson, Pamplona / Kassel, Universidad de Navarra / Reichenberger, 1998. Vv. 1249-1258.

20. Para todos estos detalles y documentación pertinente remito a Paterson, edición del auto de 1998, cuyo estudio preliminar sigo de cerca aquí.

21. Ver John C. Elliot, El Conde-Duque de Olivares, Barcelona, Crítica, 1990, p. 478.

22. Paterson, op. cit., pp. 48-49.

23. Elliot, op. cit., pp. 300-301, 500. 
Lo mismo sucede con el tercer y más importante conflicto dramatizado a través de la alegoría, el de la presencia de conversos en la España del primer tercio del siglo. En la versión autosacramental de las consultas habituales de los viernes (vv. 870 y ss.) el Judaísmo presenta un memorial pidiendo libertad y facultades de tráfico comercial, solicitud que el rey manda romper, expulsando a los judíos, los únicos solicitantes que son rechazados por el rey:

\begin{tabular}{|c|c|}
\hline REY & ¿Qué pretende el Judaísmo? \\
\hline \multirow[t]{4}{*}{ Hombre } & En tus reinos asentar \\
\hline & sus comercios, con que pueda \\
\hline & hoy tratar y contratar \\
\hline & con las más remotas islas. \\
\hline REY & $\begin{array}{l}\text { ¿Y en mi reino han de dejar } \\
\text { su Ley? }\end{array}$ \\
\hline \multirow[t]{2}{*}{ HOMBRE } & No, Señor; en ella \\
\hline & $\begin{array}{l}\text { han de vivir y han de estar } \\
\text { como están en otras partes } \\
\text { admitidos. }\end{array}$ \\
\hline \multirow[t]{8}{*}{ REY } & No, no más; \\
\hline & ese memorial romped, \\
\hline & $\begin{array}{l}\text { que en mi reino no han de estar } \\
\text { judíos, donde la } \mathrm{Fe}\end{array}$ \\
\hline & ha puesto su tribunal; \\
\hline & porque no será razón \\
\hline & ni política será \\
\hline & dar sagrado al reo, dando \\
\hline & autoridad al fiscal. \\
\hline Hombre & ¿Ninguno pide por él? \\
\hline \multicolumn{2}{|l|}{ Todos } \\
\hline REY & Pues romped el memorial. \\
\hline \multirow[t]{3}{*}{ JUDAÍSMO } & A la Reina y las Virtudes \\
\hline & ¿Por qué apacible con todos \\
\hline & y cruel conmigo estás? \\
\hline Reina & $\begin{array}{l}\text { Porque en mi amparo el judío } \\
\text { solo no tiene lugar. }{ }^{24}\end{array}$ \\
\hline
\end{tabular}

Parece evidente que la escena ha de entenderse en el marco de la polémica desatada en torno a los asentistas y financieros conversos apoyados por Olivares, y el de los incidentes antisemitas de la década de los treinta (1632 incidente del Cristo flagelado por los criptojudíos de Madrid, según declaraciones que a la Inquisición hicieron varios niños, lo que acabó en un auto de fe; 1636 auto de fe contra judaizantes...). Ingenua me parece la interpretación de Pulido Serrano, quien ve en El nuevo palacio del Retiro una defensa de Olivares:

pensamos que el verdadero objetivo de Calderón es defender al Conde Duque de los ataques que sufría por parte de todos aquellos quienes le acusaban de ser protector de los judíos y de querer traerles a vivir a España [...] El argumento de este auto se convierte en una declaración pública por parte de Olivares para intentar liberarse de

24. Calderón de la Barca Pedro, El nuevo palacio del Retiro, ed. Alan G. K. Paterson, Pamplona / Kassel, Universidad de Navarra / Reichenberger, 1998. Vv. 983-1006. 
la sospecha de filojudaísmo que sobre él caía [...] sobre el tablado [...] el público, la corte de Madrid, podía ver cómo el Conde Duque de Olivares trataba con rudo desdén y evidente desprecio al judaísmo, y cómo quedaba al margen respecto de los proyectos que hablaban de realojar judíos en tierras católicas, quedando libre de cualquier responsabilidad en este espinoso tema. ${ }^{25}$

Téngase en cuenta que el rechazo de los judíos en la escena de la consulta no proviene del Hombre, sino directamente del rey. Por lo demás la postura de Olivares en este asunto era demasiado evidente a los ojos de todos como para que la aceptación del Hombre de las órdenes del Rey pueda considerarse exoneración de las acusaciones: la actitud del rey en El nuevo palacio solo puede interpretarse como desautorización de la política del valido en este asunto, y supone un correctivo bastante violento enderezado a Olivares. Prácticamente coetáneo del auto es el venenoso texto de Quevedo Execración de los judios (fechado en Villanueva de los Infantes en 1633$)^{26}$, ferozmente antisemita y antiolivariano. Como escriben los editores de la Execración con mejores argumentos que Pulido Serrano:

desde ese antisemitismo Quevedo es también claramente antiolivarista; de tal forma que configura una actitud de oposición al valido desde la negación del mercantilismo, desde el rechazo de las posturas más políticas que justifican la razón de Estado y el maquiavelismo, aunque sea en la versión sucedánea que representa el tacitismo español del Siglo de Oro [...] atacar a los asentistas es, en suma, enfrentarse a Olivares ${ }^{27}$.

No cabe discutir ni la evidente exaltación monárquica (Felipe IV se asimila nada menos que a Cristo) ni el elogio al valido (imagen y semejanza del rey, como el Hombre es imagen y semejanza de Dios) en muchos pasajes de $E l$ nuevo palacio, pero por muy poeta cortesano que fuera Calderón no siempre se atiene a la «diplomacia» ni evita las «impertinencias» ni los enfrentamientos con poderosos cuyas posturas no comparte.

La exaltación monárquico nobiliaria, en suma, no elude el examen crítico de los mecanismos y las corrupciones del poder, especialmente en los géneros dramáticos cuya estructura responde a dicha perspectiva.

\section{LA CRÍTICA DEL PODER EN DRAMAS DE AMBICIÓN Y SOBERBIA Y OTROS GÉNEROS}

Aunque limitada por algunas salvaguardas -como la sanción final de los monarcas- es evidente la crítica de los abusos en piezas como Fuenteovejuna

25. Ignacio Pulido Serrano, "Calderón y Olivares: dependencia y antisemitismo en el barroco», Manuscrits, 1992, 10, p. 202.

26. Para las circunstancias y análisis de la Execración ver la edición de Cabo Aseguinolaza y Fernández Mosquera: Francisco de Quevedo, Execración de los judios, ed. Fernando Cabo y Santiago Fernández Mosquera, Barcelona, Editorial Crítica, 1996. En http://www.vho.org/ aaargh/fran/livres7/execracion.pdf.

27. Ibid, p. 23. 
y otros "dramas de comendador", o en obras que exponen la injusticia del poderoso -incluidos los reyes- de manera tan cruda como La estrella de Sevilla.

Tomemos el ejemplo de esta última. El duelo final del rey con los jueces sevillanos, que no se dejan intimidar por el poder abusivo, obligando al soberano a declarar la verdad de los hechos muestra de manera descarnada la inmoralidad y violencia arbitraria con las que el rey ha actuado: el rey intenta ejercer un poder, pero ha perdido la autoridad y con ella el poder que ha deformado.

Coincido con Oleza cuando expresa su «total insatisfacción» por la interpretación de La estrella «como obra destinada a reafirmar la autoridad de la monarquía por encima y a pesar de sus propios desafueros», y llega a hablar de «linchamiento moral» del monarca, resaltando el durísimo examen de las conductas del poder y la respuesta a las mismas:

no solo explora las posibilidades de desobediencia, de insumisión y aun de rebelión individual frente al poder tiránico, sino que plantea directamente la desautorización de ese poder por toda una ciudad, representada por sus nobles, pero también -y sobre todo- por sus instituciones ${ }^{28}$

Hay que tener en cuenta en este terreno la diversidad de géneros de la comedia barroca, que marcan diferentes tratamientos de la autoridad y el poder: no solamente existe la cuestión ideológica; la preceptiva literaria impone igualmente sus leyes.

El poder mal ejercido, corrompido por las pasiones particulares o por el interés, impulsado por la soberbia y la ambición, aparece en numerosas comedias, y es uno de los temas nucleares de un poeta como Calderón, al que muchos estudiosos mal informados han considerado como defensor rutinario del «sistema».

En su espléndida tragedia Los cabellos de Absalón, la fuerza directora de la obra es la ambición de este personaje, que desea incluso la muerte de su hermano Amón:

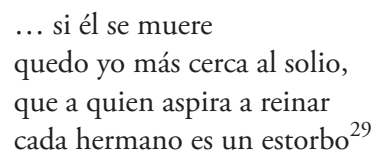

El mismo tema reaparece en muchas otras obras de Calderón. Semíramis de La hija del aire es ejemplo privilegiado de pasión por el mando, que satisface usurpando a su propio hijo.

Drama de poder y de ambición es igualmente La cisma de Ingalaterra, estudiada con gran agudeza por Ruiz Ramón y Escudero.

28. Joan Oleza, "Los géneros en el teatro de Lope de Vega», en Del horror a la risa, ed. de Ignacio Arellano, Marc Vitse y Víctor García, Kassel, Reichenberger, 1994, p. 246.

29. Pedro Calderón de la Barca, Los cabellos de Absalón, ed. Gwynne Edwards, Oxford, Pergamon Press, 1973, vv. 216-219. 
La dignidad con que retrata a Enrique VIII, y que extrańa a $\operatorname{Parker}^{30}$, no obedece en este caso a una servil contemporización con la figura real, sino a un requisito de decoro dramático que Calderón, con todo, maneja con ambigua sutileza: baste recordar que en el desenlace los nobles juran a la heredera María con condiciones y esta acepta su juramento decidida a no respetar tales condiciones: el final es una apertura a la guerra y a la destrucción, al fracaso, en suma, del rey, cuya conducta ha invertido la función propia del monarca ${ }^{31}$. Ennoblecimiento dramático del personaje, sí, pero en ningún caso disculpa ni compromiso edulcorante de la catástrofe.

Otra pieza excepcional en este sentido es El Tuzani de la Alpujarra, drama centrado en la represión que don Juan de Austria llevó a cabo contra la revuelta morisca de las Alpujarras.

Lo que le interesa es presentar una situación compleja, en la que los moriscos elevados al rango de protagonistas nobles, se observan con sus razones y su parte de justicia, y se critica la dureza y rigor poco generoso de la represión, ejemplificada en un don Juan de Austria violento, y en un soldado rapaz y asesino (Garcés) que muere a manos del justiciero Tuzaní.

En el marco de un drama de amor muy en la tradición de la morofilia, Calderón ha manifestado su oposición a la política oficial, a las tendencias y usos sociales de su época y a una concepción racista de la sociedad de su tiempo. Como subraya otro solvente historiador y calderonista, José Alcalá Zamora ${ }^{32}$, Calderón adopta una postura crítica frente a la guerra civil de la Alpujarra, defiende un tratamiento flexible de estos problemas y reflexiona sobre el poder político eludiendo las simplificaciones.

Otras dimensiones de la ética del poder, la justicia y el reclamo de la dignidad personal, se exploran en la gran comedia, bien conocida, de El alcalde de Zalamea. Y en La vida es sueño se advertirá la multiplicación de las perspectivas y de la acción, en tres temas mayores: el tema destino-libertad, el de la vida es sueńo y el tema del poder y el autodominio, temas centrales subordinan a otros, como la educación de príncipes, el modelo de gobernante, o la justicia. Si la soberbia y la violencia de Segismundo se corrigen por la experiencia y la reflexión, la soberbia y la violencia del rey Basilio acabarán provocando su derrocamiento y enseñándole que también para él la vida es sueño. Muestra de la libertad humana será precisamente la capacidad de reflexión de Segismundo y el dominio que muestra de su violencia, engendrada en parte por el mismo abuso del poder paterno.

30. Alexander A. Parker, «Henry VIII in Shakespeare and Calderon: An appreciation of $L a$ cisma de Inglaterra", en John E. Varey (ed.), Critical Studies of Calderon's Comedias, en Pedro Calderón de la Barca, Comedias, London, Gregg/Tamesis, 1973, vol. XIX, 47-77.

31. Ignacio Arellano, «"Decid al rey cuánto yerra”: algunos modelos de mal rey en Calderón», en El teatro clásico español a través de sus monarcas, ed. Luciano García Lorenzo, Madrid, Fundamentos, 2006a, pp. 149-180.

32. José Alcalá Zamora, "Individuo e historia en la estructura teatral de El Tuzani de la Alpujarra», en Calderón, Actas del Congreso Internacional, ed. Luciano García Lorenzo, Madrid, CSIC, 1983, pp. 343-364. 
En los mismos autos sacramentales que funcionaban como exaltación monárquica, se advierte que frente a esos buenos monarcas representados arquetípicamente por la estirpe de Austria se alzan los reyes absolutos y tiranos como Nembrot, Baltasar o Nabucodonosor en La torre de Babilonia, Mistica y real Babilonia o La cena del rey Baltasar que exigen de sus súbditos una adoración idolátrica, a la vez que son ellos mismos idólatras entregados a la soberbia y la vanidad ${ }^{33}$.

Mercedes Blanco ${ }^{34}$ apunta la identificación simbólica de los monarcas idólatras de Babilonia con ciertos modelos de reyes absolutos modernos que se enfrentarían a los católicos españoles. Los autos de Babilonia reflejarían de este modo los conflictos de poder y de concepciones políticas entre las monarquías española y francesa.

Otro ejemplo ilustrativo de las diversas modulaciones que recibe el tratamiento del poder puede verse en el auto sacramental de Tirso No le arriendo la ganancia, donde el género impone una visión moral del poder que no puede ser sino negativa. Todos los rasgos que caracterizan al Poder en este auto llevan el sema de 'violencia' y 'arbitrariedad': el deseo, la mudanza, la opresión, el capricho... forman una constelación negativa definitoria del concepto de 'poder' desde su primera aparición en escena armado con una pistola, hasta su propio discurso («Poder.- Donde hay Poder / poca falta el Honor hace», vv. 730-731) o el discurso de otros personajes positivos como el Honor:

¡Ah, Poder, tirano en todo!

¿Qué no derribas y ultrajas,

qué no postras, qué no pisas? ?3 $^{35}$

\section{DegradACión DE LAS FIgURAS DEL PODER EN LA COMEDIA BURLESCA}

La inevitable abrasión grotesca que imponen los requisitos del mismo género ${ }^{36}$ opera sobre figuras de autoridad y poder, que resultan convertidas en caricaturas degradadas, lo que permite al menos plantearse la posibilidad de un manejo ético/ideológico de los asuntos implicados en el ejercicio del poder y la autoridad.

En primer lugar es evidente que la mayoría de los protagonistas de las comedias burlescas son reyes o grandes nobles (duques, almirantes, príncipes...) ¿Están

33. Remito para mayor examen de estas cuestiones a Ignacio Arellano, "Conflictos de poder en los autos sacramentales de Calderón", Studi Ispanici, 2011b, 36, pp. 67-85.

34. Mercedes Blanco, «Babel-Babilonia en los autos sacramentales de Calderón: la estatua y la torre símbolos del absolutismo", en El mundo maravilloso de los autos de Calderón, Pamplona / Kassel, Universidad de Navarra / Reichenberger, 2007, pp. 63-64, 66-67.

35. Tirso de Molina, No le arriendo la ganancia, ed. Ignacio Arellano et al. en Obras completas de Tirso de Molina. Autos sacramentales I, Madrid/ Pamplona, Instituto de Estudios Tirsianos, 1998, vv. 1086-1088.

36. Para el género y sus textos principales remito a la serie de ediciones del GRISO, publicadas en Iberoamericana/Vervuert, y sus estudios preliminares. 
acaso las comedias de disparates obsesivamente interesadas en los problemas del poder y los poderosos para ofrecer una visión crítica a través de la degradación?

$\mathrm{La}$ interpretación global de la comedia burlesca conoce dos posturas fundamentales: la que advierte implicaciones de sátira (críticas, por tanto, con el poder), como hace García Lorenzo, y la que supone una dimensión estrictamente lúdica (Serralta o yo mismo ${ }^{37}$ ).

A mi juicio el protagonismo de los actantes 'poderosos' no obedece realmente a dimensiones 'políticas', sino a la cualidad paródica del género. No se puede parodiar un entremés (perteneciente él mismo a la baja comicidad, a menudo paródica en sí), ni una comedia de figurón, y poco eficaz y llamativa sería la parodia de un sector como el de capa y espada, abundante en recursos paródicos propios. Las categorías parodiables son precisamente las serias, trágicas o elevadas, plenas de reflexiones políticas y morales, desde la comedia palatina a la fiesta palaciega (comedia mitológica y/o pedagógica en el caso de Bances Candamo sobre todo), pasando por la comedia histórica y heroica, y el drama trágico (de honor o de los «de poder y de ambición ${ }^{38}$ ). En todos estos casos los modelos tienen a reyes, gobernantes, nobles y poderosos como protagonistas, y esos personajes se trasladan automáticamente a las versiones paródicas de la comedia burlesca.

A la parodia de los dramas de poder y de ambición, insertos en el marco del tema del buen gobierno corresponden muchas intervenciones del rey en Céfalo y Pocris (vv. 854 y ss. "Qué grande carga es reinar») y de su privado Antistes (vv. 990-991 «Las palabras de los reyes /son balas de pieza gruesa»). La muerte misma y el magnicidio no se libran de la burla: en El hermano de su hermana de Bernardo de Quirós, mientras bailan ridículamente, el asesino Vellido Dolfos mata al rey don Sancho con un golpe de vejiga, instrumento carnavalesco y propio del bufón:

Dale con una vejiga.
$\begin{aligned} & \text { Sancho } \\ & \text { Vellido } \\ & \text { ¿Manchósteme? }\end{aligned}$
$\begin{aligned} & \text { Debe de ser de secreto, } \\ & \text { porque yo no lo he sentido... Cáese. }\end{aligned}$

37. Para esta discusión y sus referencias bibliográficas ver Ignacio Arellano, «La degradación de las figuras del poder en la comedia burlesca», Bulletin of the Comediantes, 2013, 65. 2, pp. 1-19.

38. Ver Ignacio Arellano, «Los héroes caballerescos en los espejos del callejón del Gato de la comedia burlesca», en La comedia de caballerías, actas de las XXVIII Jornadas de Teatro Clásico de Almagro, ed. Felipe Pedraza, Rafael González Cañal y Elena Marcello, Almagro, Ediciones Universidad Castilla-La Mancha, 2006b, pp. 149-178, para las categorías que sirven de modelos, principalmente cinco subgéneros: 1) comedia mitológica o fiesta de gran espectáculo, que se parodia en burlescas como Céfalo y Pocris, de Calderón, o El premio de la virtud, anónima, sobre la historia de Belerofonte y la Quimera; 2) las de tema histórico legendario como Las mocedades del Cid de Cáncer, parodia de la comedia de Guillén de Castro, o Los condes de Carrión, anónima; 3) comedias palatinas, como Peligrar en los remedios o El rey Perico y la dama tuerta y La ventura sin buscarla (parodia de una seria de Lope de Vega); 4) comedias bélicas: El cerco de Tagarete de Bernardo de Quirós; 5) comedias del ciclo carolingio: La muerte de Valdovinos, Las bodas de Orlando, Angélica y Medoro, Durandarte y Belerma, El castigo en la arrogancia...

39. Francisco Bernardo de Quirós, El hermano de su hermana, ed. Ignacio Arellano y Carlos 
Los reyes burlescos constituyen la negación del modelo, pero la dimensión literal de sus modorras transforman la posible lección de un «espejo de príncipes» en una jocosidad intrascendente.

Es inverosímil a mi juicio que un género que servía de diversión a la corte en los días de carnaval, como es el de las comedias burlescas, pretendiera ser una crítica al rey o sus ministros. Más bien pertenecería, como el entremés, y otros modelos del disparate, al reino que llamaba Asensio de las vacaciones morales, de la chanza y del ingenio.

El PODER y LA AUTORIDAd EN EL ÁMBITO DOMÉSTICO. VARIEDADES GENÉRICAS

El poder y la autoridad no se ejerce solamente en el ámbito de los grandes. También abunda el tema en el terreno doméstico. Usualmente quien ejerce el poder es el actante paterno que impone a la mujer un matrimonio no deseado ${ }^{40}$. Hallamos versiones cómicas en el género de capa y espada y trágicas o serias en los dramas y tragedias. A las primeras pertenece Entre bobos anda el juego, comedia de Rojas en la que el padre de doña Isabel intenta forzar el deseo de su hija, que se queja del abuso:

¡Que mi padre, inadvertido darme tal marido intente! ${ }^{41}$

La estructura cómica permite el triunfo de los jóvenes y la desautorización del padre codicioso cuya elección de novio se rige por el dinero («mas si don Lucas es rico / ¿qué importa que sea necio?», dice).

Semejante defensa hace doña Inés en Donde hay agravios no hay celos, del mismo Rojas, ante los intentos de su padre para imponerle un marido:

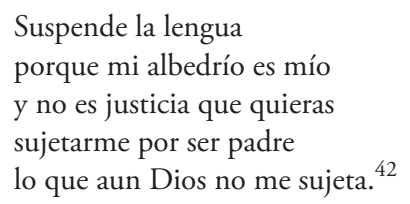

Burla directa de los propósitos paternos se hace en numerosas comedias de Tirso, como Marta la piadosa, en donde Marta y don Felipe adoptan sendas máscaras risibles (la beata y el estudiante perlático) que les permiten burlar la opresión avarienta del viejo don Gómez, víctima ridiculizada de los jóvenes.

Mata, en Dos comedias burlescas del Siglo de Oro, Kassel, Reichenberger, 2000. P. 189.

40. Algunos aspectos de este enfrentamiento en Erin Alice Cowling, "Mujeres esquivas and the paternal function", Hipogrifo. Revista de literatura y cultura del Siglo de Oro, 2015, 3.1, pp. 141 153. DOI: http://dx.doi.org/10.13035/H.2015.03.01.10.

41. Francisco de Rojas Zorrilla, Entre bobos anda el juego, ed. Maria Grazia Profeti, Madrid, Taurus, 1984. Vv. 5-6.

42. Rojas Zorrilla Francisco de, Donde hay agravios no hay celos, en Comedias escogidas, ed. Ramón Mesonero Romanos, Madrid, Atlas, 1952, BAE, 54, p. 151. 
En el género lúdico de capa y espada, manejados y burlados por los jóvenes, los viejos solo mantienen una ficción de autoridad, como el don Alonso de Los balcones de Madrid (Tirso), que pretende ser urdidor del enredo, pero no solo fracasa, sino que resulta doblemente burlado, sin saber ya si se está volviendo loco:

$$
\begin{aligned}
& \text { Jesús, Jesús, mi vejez } \\
& \text { el seso me precipita. } \\
& \text { ¿Por dónde pudiste entrar } \\
& \text { en esta pieza? }{ }^{43}
\end{aligned}
$$

Este viejo maquinador («avaro y ciego», p. 1136) para conseguir que su hija se case con un conde y evitar los amores con el galán que ella quiere, la encierra en secreto en su propia casa, intentando convencerla de que la tiene recluida en Illescas. La criada Leonor subraya esta condición maquinadora del viejo (p. 1145): pero la hija pasa a verse con su amante por los balcones de las casas contiguas, y el único enredado en su trampa es el viejo.

Al final, cuando los jóvenes triunfan, no puede menos que resignarse:

\begin{tabular}{ll}
$\begin{array}{l}\text { Don Alonso } \\
\text { Elisa }\end{array}$ & ¿Hay bellaquería más grande? \\
$\begin{array}{l}\text { Leonor } \\
\text { Don Alonso mío. }\end{array}$ & \multicolumn{1}{c}{ Viejo mío. } \\
& $\begin{array}{l}\text { Vos lo mandáis, Dios lo hace, } \\
\text { trázalo amor: contra tantos } \\
\text { ¿̇un viejo solo qué vale? }\end{array}$
\end{tabular}

En las estructuras serias los abusos de autoridad del padre pueden conducir a desenlaces funestos. Así sucede en el territorio de los dramas de honor al que pertenece Casarse por vengarse de Rojas y sobre todo en La devoción de la cruz de Calderón, donde la violencia generalizada y contaminante de Curcio solo puede ser superada por el poder de la cruz en un drama de variedad religiosa.

\begin{tabular}{|c|c|}
\hline Julia & $\begin{array}{l}\text { Bien, señor, la autoridad } \\
\text { de padre, que es preferida, } \\
\text { imperio tiene en la vida, } \\
\text { pero no en la libertad. } \\
\text { ¿Pues que supiera antes yo } \\
\text { tu intento no fuera bien, } \\
\text { y que tú, señor, también, } \\
\text { supieras mi gusto? }\end{array}$ \\
\hline Curcio & $\begin{array}{l}\text { No, } \\
\text { que sola mi voluntad } \\
\text { en lo justo o en lo injusto } \\
\text { has de tener por tu gusto. }\end{array}$ \\
\hline
\end{tabular}

No analizaré los aspectos interesantes de esta pieza, limitándome a recordar la disputa de la jornada I entre Julia y su padre sobre la libertad y la autoridad a propósito del matrimonio que Curcio quiere imponer a su hija:

43. Tirso de Molina, Los balcones de Madrid, en Obras dramáticas completas, ed. Blanca de los Ríos, Madrid, Aguilar, 1958, vol. III, p. 1150.

44. Ibid, p. 1156. 


$\begin{array}{ll}\text { Julia } & \begin{array}{l}\text { Solo tiene libertad } \\ \text { un hijo para escoger } \\ \text { estado; que el hado impío } \\ \text { no fuerza el libre albedrío. } \\ {[\ldots]}\end{array} \\ & \begin{array}{l}\text { Basta que yo lo he mirado } \\ \text { Curcio }\end{array} \\ \text { Julia } & \begin{array}{l}\text { Pues si tú vives por mí } \\ \text { toma también por mí estado. }\end{array}\end{array}$

La reivindicación de la libertad de la hija para escoger su estado enfurece al padre:

$\begin{array}{ll}\text { Curcio } & \text { ¡Calla, infame!, ¡calla, loca! } \\ & \text { que haré de aquese cabello } \\ & \text { un lazo para tu cuello, } \\ & \text { o sacaré de tu boca } \\ & \text { con mis manos la atrevida } \\ & \text { lengua que de oír me ofendo! }\end{array}$

La actitud de Curcio es solo una de las manifestaciones de la violenta locura que anula sus pretensiones autoritarias, deshaciendo su mundo y causando la perdición de su familia, salvada en último extremo por la devoción de la cruz. Para este tenebroso tirano solo existe su voluntad, que no reconoce libertad ni derecho alguno a los otros, cuyas vidas destruye.

\section{FINAL}

En suma, un repaso aleatorio de algunos ejemplos significativos confirma lo que era de esperar: que el tratamiento de los temas dramáticos, como el de la autoridad y el poder, reviste formas diferentes relacionadas no solo con actitudes éticas que pudiéramos llamar «absolutas», sino también con las convenciones y rasgos genéricos que corresponden a la variedad de modelos teatrales del Siglo de Oro: tragedias, dramas serios, comedias de capa y espada, comedias burlescas, autos sacramentales o entremeses, definen en sus propias perspectivas la presentación de todas las formas de autoridad y poder, y los conflictos posibles, negando toda idea de posturas monolíticas como la señalada por Maravall, y orientando necesariamente la interpretación de cada obra en su marco genérico.

45. Vv. 575-598. Cito por ed. Adrián Sáez, Madrid, Iberoamericana, 2014, pero modifico levemente alguna puntuación y prefiero en v. 598 la lectura de Vera Tassis. En Sáez «toma también el estado".

46. Ibid., vv. 599-604. 